\title{
Mediators of the Stress-Substance-Use Relationship in Urban Male Adolescents
}

\author{
Diana H. Fishbein, ${ }^{1,7}$ Mindy Herman-Stahl, ${ }^{2}$ Diana Eldreth, ${ }^{1}$ Mallie J. Paschall, ${ }^{3}$ \\ Christopher Hyde, ${ }^{4}$ Robert Hubal, ${ }^{5}$ Scott Hubbard, ${ }^{6}$ \\ Jason Williams, ${ }^{2}$ and Nicholas Ialongo ${ }^{6}$
}

Published online: 3 May 2006

\begin{abstract}
Exposure to chronic or severe acute stressors throughout the lifespan has been linked with numerous negative behavioral, emotional, cognitive, and physical consequences. Adolescence is considered to be a particularly vulnerable period given that the brain is experiencing dramatic developmental change during this time. The present study examined a sample of adolescents $(N=125)$ considered to be at high risk for stress exposures and drug use by virtue of their environment and low income levels to identify possible neurocognitive (i.e., impulsivity, delay of gratification, emotional perception, and risky decision-making) and social competency mechanisms that may mediate this relationship. Using Mplus, a mediational model was tested using full information maximum likelihood estimates. Risky decision-making and poor social competency skills were related to previous stressful experiences; however, only social competencies mediated the effect of stressors on reports of past year marijuana, alcohol, and polydrug use. As such, stress appears to exert its negative impact through alterations in abilities to generate and execute prosocial decisions and behaviors. Interventions that directly address the effects of stress on social competencies may be especially important for children who have experienced adversity including those exposed to parental divorce, parental psychopathology, neglect or abuse, parental death, and poverty.
\end{abstract}

KEY WORDS: stress; substance use; executive cognitive function; social competency; adolescence.

\section{INTRODUCTION}

Exposure to significant stressors during childhood and adolescence has been linked to a number of negative behavioral outcomes (Compas et al., 2001). Stressors refer to environmental circumstances or

${ }^{1}$ Behavioral Health Research Division, RTI International, Baltimore, Maryland.

${ }^{2}$ Behavioral Health Research Division, RTI International, Research Triangle Park, North Carolina.

${ }^{3}$ Prevention Research Center, Pacific Institute for Research and Evaluation, Berkeley, California.

${ }^{4}$ BioAssessments, LLC, Elkton, Maryland.

${ }^{5}$ Technology Assisted Learning Division, RTI International, Research Triangle Park, North Carolina.

${ }^{6}$ Bloomberg School of Public Health, Johns Hopkins University, Baltimore, Maryland.

${ }^{7}$ Correspondence should be directed to Diana H. Fishbein , RTI International, 6801 Eastern Avenue, Suite 203 Baltimore, Maryland 21224; e-mail: dfishbein@rti.org. conditions that threaten, harm, challenge, or exceed the psychological or biological capacities of an individual to cope, thereby inducing stress (Cohen et al., 1996). Severe or chronic stressors appear to increase propensity for psychopathology, including the initiation and progression of substance abuse (Fishbein, 2000a; Newcomb \& Bentler, 1988; Wills et al., 1996). Negative life events have been associated with the quantity and frequency of alcohol use, alcoholrelated problems, and heavy drinking, while cumulative family stress has been associated with high alcohol abuse scores (Barrera et al., 1993; Johnson \& Pandina, 1993; Windle, 1992). Moreover, negative life events predict escalation of tobacco and marijuana use (Hoffman et al., 2000; Wills et al., 2002).

Stress may exert its impact directly on substance-use behaviors or indirectly through altering the cognitive, affective, and social competency processes that underlie behavior (Sinha, 
2001). Sinha's stress-vulnerability model suggests that adverse experiences may increase risk for substance abuse via maladaptive stress responses, poor behavioral coping, and cognitive deficits. Specifically, exposure to stressors elicits a stress response involving physiological, cognitive, and affective functions. Chronic or severe stress may lead to developmental lags or disconnection within this network which impair a constellation of cognitive and emotional competencies including ability to cope, problem-solve, and use appropriate judgment in decision-making (Bar-On et al., 2003). Notably, stress and abusable drugs activate the same neural networks, sensitizing the individual to their effects and increasing both maladaptive stress responses and drug-seeking behaviors (Kreek \& Koob, 1998; Piazza \& LeMoal, 1996; Saal et al., 2003).

Optimal development and efficacy of executive cognitive functions (ECFs) and their ability to modulate perception of emotional stimuli may be compromised by the effects of stress (Arnsten \& Shansky, 2004; Moradi et al., 1999; Perry \& Pollard, 1998). ECF and emotional perception are subserved by circuitry between the brain's prefrontal cortex (PFC) and limbic system. These systems are designed to regulate behavioral inhibition, attentional control, sensitivity to rewards and penalties, decision-making, and emotional regulation, all skills critical for the execution of social skills. Development and function of this neural network is exquisitely sensitive to environmental influences; severe or chronic stress can induce neurobiological damage or developmental delays, particularly in prefrontal function. As a result, psychosocial stress can stall development of ECF and emotional regulatory skills and contribute to an inability to sustain attention, evaluate consequences, and control impulsivity (Bremner, 1999; Bremner et al., 1999; Steckler \& Holsboer, 1999). Exposure to adversity also may damage emotional appraisal processes modulated by neural circuits between the PFC with limbic-affective structures that serve to regulate and inhibit emotional responses (Bremner et al., 2004). These circuits further interact with the neuroendocrine system to produce stress-induced change in hormonal responses that fuel motivation and other adaptations (Heinrichs \& Koob, 2004), potentially leading to delays in neurobehavioral development. For example, chronic exposure to stressors can lead to elevated levels of stress hormones (e.g., cortisol; Huether, 1998), thereby inducing neurological injury evidenced anatomically as reduced hippocampal volume, and functionally as impaired memory and decision-making (Nelson \& Carver, 1998; Sapolsky, 1996). Psychophysiological studies also show effects of stress on autonomic responses such as heart rate, which, when perturbed, are associated with poor behavioral and emotional regulation, and cognitive and coping skill deficits (Gunnar \& Nelson, 1994; Sinha et al., 1998; Szabo, 1993).

ECF is not fully operational until at least age 21 , suggesting that stressors experienced during adolescence may contribute to long-lasting impairments (Thadani, 2002). As such, adolescence may be a particularly sensitive period for assessing the impact of stress on these processes as demands for coping with competing social, cognitive, biological/hormonal, and academic changes are high and have critical longterm implications for developmental risk trajectories (Petersen \& Leffert, 1995).

\section{Co-Occurring Cognitive-Emotional Functions and Social Competencies}

Social competence refers to the ability to coordinate cognition, affect, and behavior to effectively handle developmentally relevant social tasks (Weissberg et al., 1989). Social competency is strongly associated with positive developmental outcomes (Masten et al., 1999), is negatively affected by stress (Luthar, 1991), and interventions designed to enhance social competency skills have been been effective in reducing high-risk behaviors, including substance use (Botvin et al., 1995; Weissberg \& Greenberg, 1998; Zins et al., 2000). Core elements of social competence include effective communication, coping, problem-solving, conflict resolution, perception of social cues, self-efficacy, and empathy (Bloom, 1990). Impairments in social competency skills often co-occur with deficits in information processing manifested as tendencies to seek fewer social cues, make more hostile attributions, exhibit more aggression and less prosocial responses, and select riskier behavioral options (Dodge, 1986). Substance-use initiation may be a function of these social information processing skills as adolescent drug use generally takes place within highly social contexts.

ECF, Emotional Regulation, and Social Competencies Underlying Risk for Substance Use

Deficits in ECF, emotional regulation, and social competencies have been directly associated 
with substance abuse (Aytaclar et al., 1999; Giancola et al., 1998), particularly when manifested as risky decision-making, insensitivity to consequences, and impulsivity (Barratt \& Patton, 1983; Newman et al., 1987). Psychopathology related to drug abuse, such as conduct disorder, aggression, and attention deficit hyperactivity disorder, have also been characterized by these deficits (Fishbein, 2000a,b; Moss et al., 1997; Tarter et al., 1999). Perhaps not coincidentally, the incidence of adverse experiences including child abuse, psychosocial trauma, and head injury are high among substance abusers (Gianconia et al., 2000; Kendler et al., 2000).

Dysfunction of emotional centers within the limbic system may interact with ECF and social competencies to exacerbate negative behavioral outcomes by compromising the ability to accurately perceive and regulate reactions to environmental inputs. These regulatory processes are a function of physiological arousal in the autonomic nervous system (ANS), which is orchestrated by the brain (e.g., amygdala) in response to social challenges to enhance the ability to process, interpret, and react to social cues under optimal conditions. Studies using cognitive tasks and biological measures of the circuitry between the PFC and limbic system show that a combination of a propensity to negative affect, inability to shift behavioral strategies, and aberrant ANS activity in response to anticipated negative consequences is associated with substance abuse (Fishbein et al., 2006; Weiss et al., 2001). Thus, the ability to perceive one's own and others' emotional cues and regulate affective responses to these cues may be another important risk factor for drug-use initiation and escalation.

The present study is based on Sinha's premise that stress increases risk for substance use by influencing development and adequacy of ECFs, perception of emotional cues, and social competency skills; constructs that represent regulatory processes that are precursors to psychopathology, including drug use, as cited above. Specifically, this study was designed to enhance understanding of the mechanisms through which stress operates to influence drug-use behavior by (1) assessing associations between exposure to psychosocial stressors measured during early adolescence with past year alcohol and illicit drug use measured during grade 10, (2) examining the prospective relationship between stress and ECF, emotional perception, and social competencies, and (3) determining whether indices of ECF, emotional perception, and social competencies mediate the association between stress and substance use in adolescents.

\section{METHODS}

This study was conducted in collaboration with an ongoing preventive intervention study, directed by the Johns Hopkins University Prevention Intervention Research Center (JHU-PIRC) in partnership with the Baltimore City Public Schools. JHU has collected 10 years of longitudinal data from Baltimore City youth on the effects of two universal school interventions on development of distal substance abuse (see Ialongo et al., 1999, 2001; Kellam et al., 1994, for more information).

\section{Study Participants}

In 1993, 678 first-graders were recruited from elementary schools primarily located in western Baltimore (86.8\% African American), depicted as a high-risk urban area by virtue of factors such as crime rates, drug abuse and trafficking, low income, and single-mother homes. Just under twothirds $(63.4 \%)$ of the children were receiving free or reduced-price lunch. JHU-PIRC obtained written parental consent for $550(81 \%)$ of the youth to participate in annual assessments through grade 10, which is the year of their participation in the present study.

A subset of 125 males was recruited in the ninth grade (mean age 16.1) to participate in a separate study to identify neurocognitive, emotional, and physiological mechanisms in variable behavioral change in response to a brief laboratory intervention. Parental permission was obtained for 61 students (out of 78) with conduct disorder (CD) and concomitant risk behaviors, including delinquency and school misconduct. Diagnoses were based on lay interviewer administration of the C-DISC-IV to the youth and a parent; a diagnosis generated by either was considered for this characterization. Sixty-four youth without a CD diagnosis or other risk behaviors (out of 93) were successfully recruited to ensure adequate variation in risk behaviors, although $\mathrm{CD}$ was not the basis for assessing group differences. The total number of refusals was 47 ( 20 with and 27 without $C D$ ). Only males were recruited given that the females had a 
very low rate of $C D$ diagnoses. Their mean full scale IQ was $82(S D=13) .{ }^{8}$ Monetary compensation and a break were provided.

\section{Baseline Test Battery}

The test battery was specifically designed to measure impulsivity, risky decision-making, delay of gratification, facial recognition, and social competencies, including emotional control, interpersonal communication skills, beliefs supporting aggression, hostility, and conflict resolution style. These tasks were selected due to their conceptual consistency with the phenomenology of drug abuse and because they provide measures of functions that have been specifically related to the neural network discussed earlier shown to be influenced by stress. Furthermore, each cognitive and emotional task has been shown in neuroimaging studies to activate the PFC and functionally relevant regions of the limbic system. Knowledge regarding the functional neuroanatomy of a cognitive task has potential implications for understanding the pathophysiology of behavioral dysregulation and provides a mechanistic account of how interventions mediate their effects (Bremner, 2003; Charney \& Deutsch, 1996). These neurocognitive measures are, by nature, decontextualized to generate a relatively unbiased measure of the level of cognitive and emotional functioning, irrespective of culture and context. Social competency skill measures are, conversely, contextualized given that they reflect behaviors that are, by nature, elicited in the social environment of adolescents. See test battery details in Fishbein et al. (in press).

IQ

An estimate of IQ was derived from the Vocabulary and Block Design subtests of the Wechsler Intelligence Scale for Children-III (WISC-III; Wechsler, 1974, 1991). The combination of these subtests correlates positively at more than .90 with Full Scale IQ (Sattler, 1988). Adjustments for IQ were made in all statistical analyses to focus on higher order cognitive functions that are subserved by basic intellectual processes.

${ }^{8}$ IQ was based on the Vocabulary and Block Design components of the WISC-III. Both the scores were relatively low in this population; however, mean scores on the vocabulary portion, which is sensitive to experience and level of education, were particular low.
Risky Decision-Making and Sensitivity
to Consequences

The Dice Task was adapted for adolescents from the Rogers Decision-Making Task (RDMT), developed to dissect cognitive components implicated in sensitivity to consequences and risk taking. This task consistently activates the orbitofrontal portion of the PFC (Fishbein et al., 2005b; Rogers et al., 1999a,b), an area known to modulate decisionmaking, social skills, impulse control, and goal-driven behaviors. The goal is to earn as many points as possible in gambling-type scenarios with known odds of winning or losing a particular number of points. Larger rewards are associated with the least likely outcomes, thus capturing the conflict inherent in risktaking situations. Performance measures generated by this task are (1) number of the riskiest decisions (where the largest reward is associated with a higher possibility of losing that same number of points), (2) mean deliberation time for the entire task, and (3) mean deliberation time for riskiest decision.

\section{Impulsivity and Distractibility}

The Logan Stop-Signal Task (Solanto et al., 2001) was used to measure impulsivity and distractibility (see Nichols \& Waschbusch, 2004 for reliability and validity). This task has been shown to activate the right hemispheric anterior cingulate cortex, supplementary motor area, and inferior prefrontal and parietal cortices, which modulate error monitoring, interference control, and task management ( $\mathrm{Ru}-$ bia et al., 2001). The task's baseline portion requires participants to press particular keys when asterisks or circles are displayed quickly on a computer screen. The "active" portion presents a distracting tone at different delay intervals after the stimulus appears and participants must shift their response to a third key when this occurs. Feedback is presented for each response. Measures generated by this task include (1) number of correct responses for baseline, (2) number of correct responses for the short tone delay and the lengthy tone delay portions of the task, (3) commission errors, and (4) omission errors.

\section{Delay of Gratification}

The Choice Delay Task (Sonuga-Barke et al., 1992) was used to assess ability to delay gratification 
(see Nichols \& Waschbusch, 2004 for its reliability and validity). Imaging research (Davis et al., 2002) suggests that this task activates the anterior attention system (Posner, 1995) and paralimbic cortex (McClure et al., 2004), responsible for the perception and experience of emotionally salient stimuli. The task creates a tension between selecting an option that requires (1) a longer wait for a larger reward, and (2) a smaller immediate reward. Scores include (1) number of rapid responses that earned few points, (2) average reaction time, (3) omission and commission errors, and (4) total number of points.

\section{Emotional Perception}

The Facial Recognition Task (Ekman \& Friesen, 1975) measures the ability to accurately identify emotional expressions in other people's faces (see Young et al., 2002 for reliability and validity information). This ability has been directly related to the function of the brain's amygdala (Morris et al., 1996) and is shown to be impaired in children and adults with externalizing disorders, such as conduct disorder, violence, and drug abuse (Blair et al., 1999; Phillips et al., 1997). One of six emotions (i.e., happiness, anger, disgust, surprise, sadness, and fear) are identified that best describe the face for 60 expressions in varying intensities. This task produces measures of number of correct responses for each facial expression plus a total correct score.

\section{Social Competence}

Social competence was measured using three interactive virtual reality (VR) vignettes and three questionnaires assessing beliefs supporting aggression, conflict resolution styles, and hostility (see Paschall et al., 2004 for reliability and validity of the questionnaires). Three VR vignettes simulated real interpersonal verbal interactions with a teenager (see Fishbein et al., 2006 and Hubal et al., 2003, 2004 for full details). An algorithm was developed by which the virtual teenager would initially entice risky behavior but gradually back off if the participant demonstrated appropriate avoidance and/or deescalation behavior. These situations represented actual experiences of urban minority adolescents that are used for role plays in prevention programs such as PACT (Yung \& Hammond, 1998) and Life Skills Training (Botvin, 2000; Botvin et al., 1995) and, thus, include situations and language appropriately contextualized for this population.

Measures of engagement and social competency skills were based on ratings of adolescents' verbal and nonverbal interaction with the virtual teenage character. A principal components analysis was used to reduce seven dimensions-general engagement, verbalizations, emotional control, information seeking, expressing own preferences, compromise/negotiation, and being nonprovocative (see Paschall et al., 2004 for more information) creating a two-factor solution consisting of emotional control and interpersonal communication skills (Cronbach's alpha for these scales were .88 and .91 , respectively).

\section{Beliefs Supporting Aggression}

Beliefs supporting aggression were assessed using a 10-item scale adapted from a study by Slaby and Guerra (1988). Participants were asked how strongly they agreed or disagreed with such statements as, "It makes you feel big and tough when you push someone around" and "A guy who doesn't fight back when other kids push him around will lose respect." A mean response score was computed, with a higher score indicating more beliefs supporting aggressive behavior.

\section{Conflict-Resolution Style}

Conflict-resolution style was assessed using four hypothetical situations (Slaby \& Wilson-Brewer, 1992). Participants were presented with a confrontational situation and then asked what they would probably do in that situation. For each vignette, there were options for verbally aggressive, informationseeking, passive, verbally assertive, and physically aggressive responses. A mean response score was computed for each participant, with a higher score indicating a more aggressive conflict-resolution style.

Hostility

Hostility was assessed using a five-item scale based on the Symptom Checklist-90 (Derogatis et al., 1973). An average score was computed, with a higher score indicating more hostility. 


\section{Substance Use}

The drug and alcohol use component of the youth interview (consistent with the National Monitoring the Future Survey; Johnston et al., 2004) was self-administered in the larger longitudinal JHU study via a computer with audio and visual presentation of the questions. Drug-use measures obtained during grade 10 were used as the dependent variables for this study: Past year measures of marijuana, tobacco, and alcohol use were assessed with three binary variables indicating use or no use. A fourth outcome, polydrug use, was formed by adding the number of types of substances that each participant reported using in the past year. Substances that were included in this index were tobacco, alcohol, marijuana, crack, cocaine, inhalants, heroin, and ecstasy.

\section{Stressors}

Adolescents' experience of negative life events was measured in the 6th through 8th grades using the Life Events Questionnaire Adolescent Versions (LEQ-C \& LEQ-A; adapted from Coddington, 1972). The LEQ-A, a checklist of stressful life events for adolescents, was modified to include a broader range of events relevant to adolescence and familyrelated stressors. Items were added from other relevant validated measures including the Adolescent Perceived Events Scale (APES) (Compas et al., 1985) and the Adolescent-Family Inventory of Life Events and Changes (A-FILE) (McCubbin et al., 1983). The event list covered 21 circumstances common in the contexts of inner-city adolescents' lives such as illness or death of family members, getting into legal trouble, moving, being in a serious accident, and witnessing or being victimized by violence. A sum score was calculated with each event having an equal weight. To obtain a mean, prospective measure of stress, negative life event counts were averaged across grades 6 , 7 , and 8 . The mean negative life event count ranged from 0 to 7 (mean $=1.91, S D=1.61) .{ }^{9}$ Items include both negative and traumatic life events, which may elicit more severe psychological and biological responses. However, all events were given equal

\footnotetext{
${ }^{9}$ Two additional mean stress measures were constructed consisting of stressors related to violence and stressors not associated with violence. Because results were comparable, only those for the overall stress measure are presented.
}

weighting as research suggests that unweighted cumulative indicators of stressors are the most reliable method of objectively assessing stress exposure and control for the bias induced by differential stress appraisals and reactions (Herbert \& Sheldon, 1996). There was significant consistency in stress reports from year to year, with correlations in overall stress ranging from .344 (grade 6 to grade 8) to .508 (grade 7 to grade 8 ).

\section{Statistical Analyses}

\section{Development of Mediator Constructs}

To assess the direct and mediated influence of stress on substance use, a multiple mediator model was used. Because many of these indicators included measures with multiple response types and responses were not necessarily identically scaled, latent factors were estimated and used as mediators for some constructs. Factors were evaluated independently of the others in separate measurement models. The latent risky decision factor included those four scores that reflect the highest risk choices (e.g., 1/5 odds of winning with 90 points at stake), with high scores indicating a higher risk-taking proclivity. Five variables assessing correct attribution of facial expressions (happiness, surprise, disgust, sadness, and anger) were used to define a second hypothesized mediating factor-emotional perception. A social competence factor was comprised of the emotional composure and interpersonal communication scores from the virtual reality vignettes in addition to the Beliefs Supporting Aggression Scale, ConflictResolution Style Scale, and Hostility Subscale. The composite factor was scaled such that high scores indicated low social competence. Two additional mediators were created from the most representative single item for each construct. Impulsivity was an observed variable using the overall early signal presses during the tone task trials. Total points accumulated in the Choice Delay Task were used as the measure of delay of gratification. Higher scores indicate more impulsivity or ability to delay gratification.

Latent factors were evaluated with Mplus version 3.11 (Muthén \& Muthén, 1998-2004) using full information maximum likelihood (ML) to estimate parameters without bias from Missing at Random (MAR) missing data. Social competence and emotional perception had very good model fits with nonsignificant Chi-square values, 
Table 1. Mediator Correlations

\begin{tabular}{|c|c|c|c|c|c|}
\hline & $\begin{array}{l}\text { 1. Low social } \\
\text { competence }\end{array}$ & $\begin{array}{l}\text { 2. High emotional } \\
\text { perception }\end{array}$ & $\begin{array}{l}\text { 3. High risky } \\
\text { decision-making }\end{array}$ & $\begin{array}{l}\text { 4. High delay of } \\
\text { gratification }\end{array}$ & $\begin{array}{l}\text { 5. High } \\
\text { impulsivity }\end{array}$ \\
\hline 1. Low social competence & - & $-0.264^{*}$ & $0.261^{*}$ & -0.038 & -0.111 \\
\hline 2. High emotional perception & - & - & $-0.354^{* *}$ & 0.120 & 0.020 \\
\hline 3. High risky decision-making & - & - & - & -0.104 & -0.133 \\
\hline 4. High delay of gratification & - & - & - & - & -0.169 \\
\hline 5. High impulsivity & - & - & - & - & - \\
\hline
\end{tabular}

root mean square error of approximation (RMSEA) under .04, standardized root mean residual (SRMR) values under .035, and comparative fit indices (CFIs) greater than .95. The risky decision factor fit somewhat less well, with a significant Chisquare, $\mathrm{CFI}=.90, \mathrm{RMSEA}=.20$, and SRMR of .048 . Inter-correlations of these factors are presented in Table 1.

\section{Mediational Analyses}

The full mediation model was estimated as a structural equation model in Mplus with the average stress measure across grades 6th through 8th, predicting all five mediators (measured at grade 9) and substance-use outcomes (measured in grade 10) of past year alcohol, tobacco, marijuana, and polydrug use (see Fig. 1 for model). Mediated effects were estimated as the product of the path coefficient linking stress to a mediator, and the path coefficient linking that mediator to an outcome. In all, 20 indirect effects were evaluated. The standard error of each mediated effect was estimated using the multivariate delta solution (Sobel, 1982) and significance was established by comparing the estimate of each effect divided by its standard error to the normal distribution. IQ was included as a control variable predicting all mediators and outcomes. The potential effects of CD were covaried, however, this did not alter the results; thus, models were tested without this covariate. Missing data, while a small issue as 113 of the 120 participants had full records, were again incorporated using full information ML estimation, which allowed estimation of the model with the full sample. A weighted least squares algorithm (WLSMV; Muthén \& Muthén, 1998-2004) was used to properly estimate effects on the binary substance-use measures.

\section{RESULTS}

Stressful Events and Substance Use

The frequencies of the negative life events and substance use within this sample are presented in Table 2. In general, adolescents reported a high level of negative life events in the middle school years and serious illness or death within the family were not uncommon. Also, substance-use rates were noteworthy: $64 \%$ drank alcohol within their lifetime, $43 \%$ used tobacco, and $40.8 \%$ used marijuana.

Mediation of Stress-Drug-Use Relationship by Neurocognition and Social Competency

Table 3 displays the estimates of the impact of stress on each of the mediators, the effect of the mediators on each of the substance-use outcomes, and the estimate of the indirect effect of stress on substance use through each of the mediators. This multiple mediator model fit the data reasonably well $\left(\chi^{2}(47)=82.088, p<.01 ; \mathrm{CFI}=.84\right.$; RMSEA $=.077$; and weighted root mean square residual $($ WRMR $)=.86)$. The WRMR statistic is most relevant for models such as this with categorical outcomes (Muthén \& Muthén, 1998-2004), with values under 1.0 suggesting adequate fit. As shown in Table 1 , the five mediating constructs were distinct, with nonsignificant correlations. These were incorporated in the model so as to estimate the unique mediated effects of each construct.

Early adolescent stress significantly influenced two of the hypothesized mediators. Risky decision-making was significantly higher in those who reported greater stress in the prior 3 years. Stress also was significantly associated with lower 


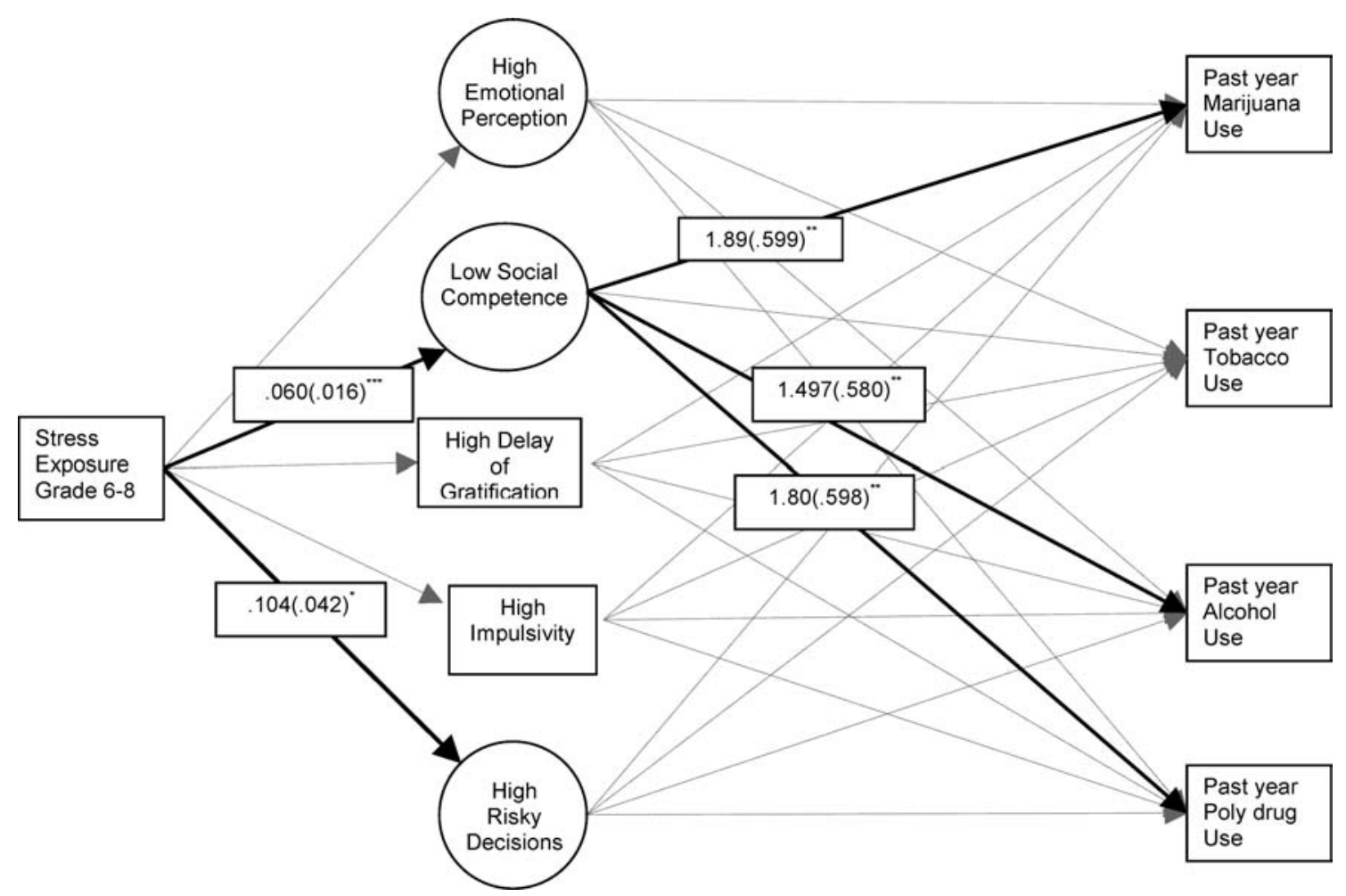

Fig. 1. Social competency mediates relationship between stress and substance use.

social competency, indicating increased hostility and beliefs supporting aggression, less composure and less effective communication. However, only the social competency construct was significantly related to any of the substance-use measures. Lower social competency was linked with greater past year use of marijuana, alcohol, and greater polydrug use. The mediated effect estimate was significant for these three outcomes as well, indicating that the effect of stress on these three types of use was significantly mediated by the social competency construct (Fig. 1). Also in all three cases, the direct effect of stress on substance use was nonsignificant. IQ had no significant direct effects and was not involved in any alternative mediated effects in the model.

An alternative 3 path mediational model, with stress predicting ECF and ECF predicting social competence and then drug use, was also tested given the inherent uncertainty regarding temporal precedence: Does ECF co-occur with or underlie social competency skills? All indirect effects were nonsignificant. Thus, to summarize, an averaged index of stress in grades 6,7 , and 8 predicted composite mea- sures of low social competency and risky decisionmaking. The mediation model revealed an indirect impact of stress on alcohol, marijuana, and polydrug use that was transmitted through deficits in social competency.

\section{DISCUSSION}

Using a stress-vulnerability model, this prospective study examined whether early adolescent stress was associated with cognitive and emotional functions and social competency indicators, and whether these mechanisms mediated the impact of stress on substance use. Our model is grounded in work by Sinha (2001) and others (Charney, 2004) suggesting that stress influences drug use via alterations in the neurochemical and neurocognitive processes that activate behavioral responses. This transdisciplinary approach will advance understanding of the neural substrates of psychopathology and enable increasing specificity in the identification of at-risk individuals and the tailoring of interventions to address individuals' specific liabilities (Fishbein, 2000a). 
Table 2. Frequency of Negative Life Events (Averaged Across Grades 6, 7, and 8) and Past Year Substance Use (Measured at Grade 10$), N=125$

\begin{tabular}{lc}
\hline \multicolumn{1}{c}{ Life events-Items } & $\begin{array}{c}\text { Averaged proportion } \\
\text { of youth reporting } \\
\text { event in grades 6, 7, or }\end{array}$ \\
$8(\%)$
\end{tabular}

Latent constructs were derived as indicators of neurocognitive and behavioral functions, including risky decision-making, emotional perception, and social competence. These composite mediators tapped the regulatory mechanisms of interest, evidenced good model fits, and were related as expected. Specifically, significant intercorrelations were found between social competence and risky decision-making and emotional perception, and between risky decision-making and emotional perception. These findings suggest that relative deficits in risky decision-making and social competence may manifest as associated characteristics that place individuals at risk for maladaptive behavioral responses. On the other hand, not all of these functions were predictive of drug use, as discussed later, implying that they play a differential role in risk behaviors.
Furthermore, an averaged index of stress reported in grades $6-8$ predicted risky decision-making and social competency skills as measured in grade 9. This finding is consistent with research suggesting that stress may alter neurocognition via effects on development and function of the prefrontal cortex, leading to impaired decision-making, reduced sensitivity to penalties and increased risk proclivity (Bremner, 1999; Fishbein, 2000b). These results also support research showing that children exposed to stressful experiences evidence significant social skill deficits (Rutter, 1999). The specific pathogenic pathways for social-cognitive vulnerabilities are still unclear but likely result from the deleterious impact of stress on brain development. Stress is linked with dysregulation of biological reward pathways in the central nervous system (CNS) and the stress response systems (Kreek \& Koob, 1998), which enhances vulnerability to psychopathology (De Bellis, 2002). Data did not tap into early childhood trauma; thus, this study could not discern whether relative deficits observed in adolescents with higher levels of recent stressor exposures were incurred in adolescence or earlier in childhood (i.e., due to cumulative exposures). However, research suggests that adolescence is a particularly vulnerable period characterized by heightened sensitivity to various types of stressors, from psychosocial adversity to drug use itself (Arnsten \& Shansky, 2004). It is therefore possible that stress experienced in adolescence could also contribute to developmental delays or functional deficits in neurobehavioral processes (Arnsten \& Shansky, 2004; Spear, 2000).

Primary results of this study suggest that the effect of stress on reports of marijuana, alcohol, and polydrug use was mediated through the construct social competence. As such, stress appears to exert its negative impact through alterations in abilities to generate and execute prosocial decisions and behaviors. This finding supports extant research illuminating the importance of competence in childhood resilience. Resilient children evidence greater competence in multiple domains (e.g., social, academic, coping) despite significant threats to development (Luthar, 1991; Masten et al., 1995).

Other neurocognitive functions such as impulsivity, delay of gratification, and emotional perception did not serve as mediators of the stress-drug-use relationship. Though a large body of literature suggests that these functional deficits are implicated in substance abuse risk, in the present sample, they were not directly related to stress exposures and did 


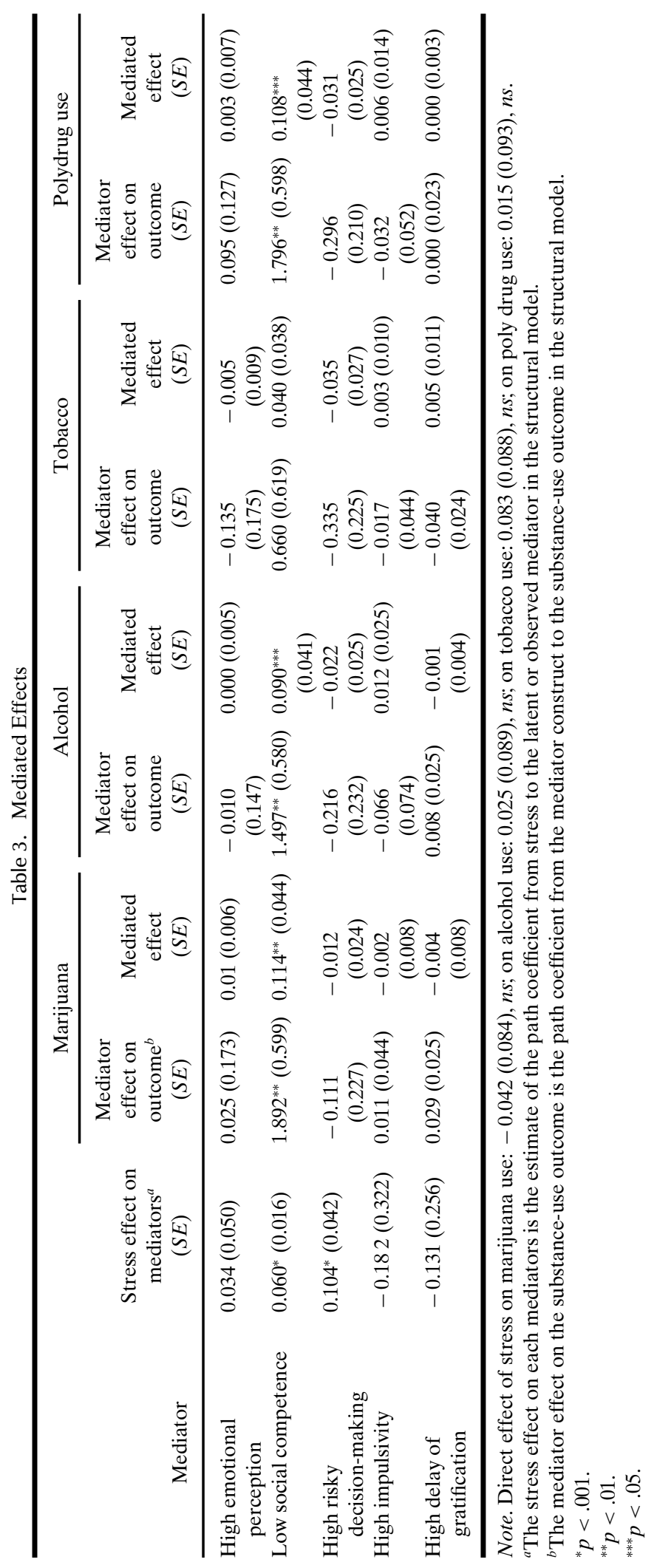


not play a mediating role in the relationship under study. Social competence and risky decision-making may differ from these unrelated functions in terms of their complexity and the social context in which they occur or are triggered; the measures of impulsivity, delay of gratification, and emotional perception used in this study were without social context and elicited only very simple behaviors or reactions. Several other studies have found more complex neuropsychological and behavioral measures to more aptly characterize complex forms of psychopathology than simple measures (Fishbein et al., 2005a; Rogers \& Robbins, 2001). Also, tobacco use was not predicted by any of these latent constructs, possibly due to the prevalence of smoking in this population and the overall attitude that smoking is not a "high-risk" behavior and is not generally used for its obvious psychoactive effects (although science has proved that attitude wrong on both counts for several decades).

Several limitations of this study should be noted. First, analyses were conducted on a small sample of male adolescents, predominantly African Americans, from low-income and working-class neighborhoods in Baltimore. Thus, findings may not be generalizable to other populations, although these demographics describe many populations that are often the target of universal prevention programs (e.g., Griffin et al., 2003). Second, negative and traumatic events were given equal weight in the analyses despite potential differences in severity; however, studies of life event measures have found that simple counts of negative events are as reliable as weighted counts in predicting psychopathology (Herbert \& Sheldon, 1996). Moreover, our method of assessing stress precluded examination of the influence of severe acute versus chronic stress; however, research suggests that both types of stressors are associated with negative emotional and behavioral outcomes. Third, our measure of social competence is heterogeneous; thus, it is unknown which dimensions of social competence are driving the mediation finding. Additionally, measures of mediating constructs were obtained only during grade 9 , and we were unable to explore changes in these constructs over time and in relation to changes in stress exposure. Importantly, another possible explanation for the association between stressors and ECF is that stressors may not be "random" events, but may reflect person-environment selection guided by factors such as personality (e.g., impulsivity) (Kendler et al., 1993). Thus, a plausible alternate model is that ECF may predate exposure to high-stress environments; however, the lack of measures prior to stress exposure precludes a test of this model. Another model that could not be sufficiently tested due to the small sample size would examine the "causal chain" to determine whether ECF underlies social competence. Future research should consider the temporal ordering and roles of relevant variables along these lines. Finally, given the preponderance of violencerelated events in our stress measure and the dimensions of social aggression being tapped in the social competence measure, it is possible that the associations amongst the major constructs reflect an individual's propensity toward aggression. However, results did not change when we controlled for diagnoses of conduct disorder. Furthermore, results remained the same when we excluded all violence-related events from the stress measure and alternatively, when we excluded all of the non-violence-related events. The constructs modeled in the present study extend beyond violence per se, and are relevant to a number of problem behaviors that may have occurred from regulatory deficits caused or exacerbated by a series of harsh social and environmental inputs that place excessive demands on the growing adolescent brain.

\section{Implications for Prevention}

These results add to a vast body of literature showing the negative effects of stress on developmental outcomes. The population under study has been characterized as one with a relatively high prevalence of exposure to severe and cumulative psychosocial stressors. Communities such as Baltimore City that are predominantly low income with singleparent homes and lack of access to social services are characterized by high rates of drug abuse, delinquency, and other high-risk behaviors (Griffin et al., 2003). As a result, they are often targeted by universal prevention programs that tend to influence the behavior of some subgroups more than others. Given relations between stress and drug use and the potential for such exposures to impair development and function of prefrontally modulated cognitive functions, it is critical that programs are designed to reduce exposure to stressors and strengthen vulnerable underlying neural processes.

Early intervention with at-risk children is a powerful means for preventing later psychopathology (Carter et al., 2004). Several preventive programs designed to enhance decision-making and social competence have been shown to be effective with 
children and adolescents. As such, these programs should be institutionalized, and effective policies should be put in place to ensure that individuals who have access to high-risk populations such as teachers or pediatricians have procedures and resources available for referring children and families to effective prevention services. Additionally, our findings illuminate the importance of tailoring preventive interventions to match the specific liabilities of individuals. For instance, individuals with neurocognitive deficits may process and respond to interventions differently than others and may require unique strategies to be able to absorb the preventive messages (Fishbein et al., 2006). Interventions will need to draw on cross-disciplinary approaches including cognitive-behavioral strategies, stress management, parenting interventions, behavioral rehabilitation, and psychoeducational approaches to holistically address the multitude of needs exhibited by children and adolescents exposed to severe or chronic stress. Future research should expand on both the scientific knowledge regarding the neurobiological underpinnings of social behaviors and the prevention theories and strategies necessary to effectively intervene to ensure healthy development of all children and adolescents.

\section{ACKNOWLEDGMENTS}

We would like to thank the team at Johns Hopkins University PIRC for their assistance in providing access to study participants and data collected for the longitudinal study.

\section{REFERENCES}

Arnsten, A. F., \& Shansky, R. M. (2004). Adolescence: Vulnerable period for stress-induced prefrontal cortical function? Introduction to part IV. Annals of the New York Academy of Science, 1021, 143-147.

Aytaclar, S., Tarter, R. E., Kirisci, L., \& Lu, S. (1999). Association between hyperactivity and executive cognitive functioning in childhood and substance use in early adolescence. Journal of the American Academy of Child and Adolescent Psychiatry, $38(2), 172-178$.

Bar-On, R., Tranel, D., Denburg, N. L., \& Bechara, A. (2003). Exploring the neurological substrate of emotional and social intelligence. Brain, 126, 1790-1800.

Barratt, E. S., \& Patton, J. H. (1983). Impulsivity: Cognitive, behavioral and psychophysiological correlates. In $\mathrm{M}$. Zuckerman (Ed.), Biological bases of sensation seeking, impulsivity and anxiety (pp. 77-116). Hillsdale, NJ: Erlbaum.

Barrera, M., Jr., Li, S. A., \& Chassin, L. (1993). Ethnic group differences in vulnerability to parental alcoholism and life stress: A study of Hispanic and non-Hispanic Caucasian ado- lescents. American Journal of Community Psychology, 21(1), 15-35.

Blair, R. J., Morris, J. S., Frith, C. D., Perrett, D. I., \& Dolan, R. J. (1999). Dissociable neural responses to facial expressions of sadness and anger. Brain, 122, 883-893.

Bloom, M. (1990). The psychosocial constructs of social competency. In T. P. Gullota, G. R. Adams, \& R. Montemayor (Eds.), Developing social competency in adolescence (pp. 1127). Newbury Park, CA: Sage.

Botvin, G. J. (2000). Preventing drug abuse in schools: Social and competence enhancement approaches targeting individuallevel etiologic factors. Addictive Behavior, 25(6), 887897.

Botvin, G. J., Baker, E., Dusenbury, L., Botvin, E. M., \& Diaz, T. (1995). Long-term follow-up results of a randomized drug abuse prevention trial in a white middle-class population. Journal of the American Medical Association, 273, 11061112.

Bremner, J. D., Vermetten, E., Vythilingam, M., Afzal, N., Schmahl, C., Elzinga, B., \& Charney, D. S. (2004). Neural correlates of the classic color and emotional stroop in women with abuse-related posttraumatic stress disorder. Biological Psychiatry, 55(6), 612-620.

Bremner, J. D. (1999). Alterations in brain structure and function associated with post-traumatic stress disorder. Seminars in Clinical Neuropsychiatry, 4(4), 249-255.

Bremner, J. D. (2003). Functional neuroanatomical correlates of traumatic stress revisited 7 years later, this time with data. Psychopharmacology Bulletin 37(2), 6-25.

Bremner, J. D., Southwick, S. M., \& Charney, D. S. (1999). The neurobiology of posttraumatic stress disorder: An integration of animal and human research. In P. Saigh \& J. D. Bremner (Eds.), Posttraumatic stress disorder: A comprehensive text (pp. 103-143). New York: Allyn \& Bacon.

Carter, A. S., Briggs-Gowan, M. J., \& Davis, N. O. (2004). Assessment of young children's social-emotional development and psychopathology: Recent advances and recommendations for practice. Journal of Child Psychology and Psychiatry, 45(1), 109-134.

Charney, D. (2004). Psychobiological mechanisms of resilience and vulnerability: Implications for successful adaptation to extreme stress. American Journal of Psychiatry, 161(2), 195216.

Charney, D. S., \& Deutch, A. (1996). A functional neuroanatomy of anxiety and fear: Implications for the pathophysiology and treatment of anxiety disorders. Critical Reviews in Neurobiology, 10(3-4), 419-446.

Coddington, R. D. (1972). The significance of life events as etiologic factors in the diseases of children. II. A study of a normal population. Journal of Psychosomatic Research, 16(3), 205-213

Cohen, Y., Spirito, A., Sterling, C., Donaldson, D., Seifer, R., Plummer, B., Avila, R., \& Ferrer, K. (1996). Physical and sexual abuse and their relation to psychiatric disorder and suicidal behavior among adolescents who are psychiatrically hospitalized. Journal of Child Psychology and Psychiatry, 37(8), 989-993.

Compas, B. E., Connor-Smith, J. K., Saltzman, H., Thomsen, A., \& Wadsworth, M. E. (2001). Coping with stress during childhood and adolescence: Problems, progress and potential in theory and research. Psychological Bulletin, 127(1), 87-127.

Compas, B. E., Davis, G. E., \& Forsythe, C. J. (1985). Characteristics of life events during adolescence. American Journal of Community Psychology, 13(6), 677-691.

Davis, E. P., Bruce, J., \& Gunnar, M. R. (2002). The anterior attention network: Associations with temperament and neuroendocrine activity in 6-year-old children. Developmental Psychobiology, 40(1), 43-56. 
De Bellis, M. D. (2002). Developmental traumatology: A contributory mechanism for alcohol and substance use disorders. Psychoneuroendocrinology, 27, 155-170.

Derogatis, L. R., Lipman, R. S., \& Covi, L. (1973). SCL-90: An outpatient psychiatric rating scale-Preliminary report. Psychopharmacology Bulletin, 9(1), 13-28.

Dodge, K. A. (1986). A social information processing model of social competence in children. In M. Perlmutter (Ed.), Minnesota symposium in child psychology (pp. 77-125). Hillsdale, NJ: Lawrence Erlbaum.

Ekman, P., \& Friesen, W. V. (1975). Pictures of facial affect. Palo Alto, CA: Consulting Psychologists Press.

Fishbein, D. H. (2000a). The import of neurobiological research to the prevention of antisocial behavior and drug abuse. Prevention Science, 1(2), 89-106.

Fishbein, D. H. (2000b). Neuropsychological dysfunction, drug abuse and violence: Conceptual framework and preliminary findings. Criminal Justice and Behavior, 27, 139-159.

Fishbein, D. H., Hyde, C., Eldreth, D., London, E. D., Matochik, J., \& Ernst, M., et al. (2005a). Cognitive performance and autonomic reactivity in abstinent drug abusers and nonusers. Experimental and Clinical Psychopharmacology, 13(1), 2540.

Fishbein, D. H., Eldreth, D. L., Hyde, C., Matochik, J. A., London, E. D., \& Contoreggi, C., et al. (2005b). Risky decision making and the anterior cingulate cortex in abstinent drug abusers and nonusers. Cognitive Brain Research, 23, 119-136.

Fishbein, D. H., Hyde, C., Eldreth, D., Paschall, M. J., Tarter, R., Das, A., Hubal, R., Ialongo, N., Hubbard, S., \& Yung, B. (2006). Neurocognitive skills moderate urban male adolescents' responses to preventive intervention materials. Drug and Alcohol Dependence 82: 47-60.

Giancola, P. R., Mezzich, A. C., \& Tarter, R. E. (1998). Disruptive, delinquent and aggressive behavior in female adolescents with a psychoactive substance use disorder: Relation to executive cognitive functioning. Journal of Studies on Alcohol, 59(5), 560-567.

Gianconia, R. M., Reinherz, H. Z., Hauf, A. C., Paradis, A. D., Wasserman, M. S., Langhammer, D. M., Gunnar, M., Kirshbaum, C., \& Hellhammer, D. (2000). Comorbidity of substance use and post-traumatic stress disorders in a community sample of adolescents. American Journal of Orthopsychiatry, 70(2), 253-262.

Griffin, K. W., Botvin, G. J., Nichols, T. R., \& Doyle, M. M. (2003). Effectiveness of a universal drug abuse prevention approach for youth at high risk for substance use initiation. Preventive Medicine, 36(1), 1-7.

Herbert, T. B., \& Sheldon, C. (1996). Measurement issues in research on psychosocial stress. In H. B. Kaplan (Ed.), Psychosocial stress: Perspectives on structure, theory, life course, and methods (pp. 293-333). New York: Academic Press.

Hoffmann, J. P., Cerbone, F. G., \& Su, S. S. (2000). A growth curve analysis of stress and adolescent drug use. Substance Use and Misuse, 35, 687-716.

Hubal, R. C., Deterding, R. R., Frank, G. A., Schwetzke, H. F., \& Kizakevich, P. N. (2003). Lessons learned in modeling virtual pediatric patients. Studies in Health Technology and Informatics, 94, 127-130.

Hubal, R. C., Fishbein, D. H., \& Paschall, M. J. (2004). Lessons learned using responsive virtual humans for assessing interaction skills. Proceedings of the Interservice/Industry Training, Simulation and Education Conference (pp. 989-999). Arlington, VA: National Training Systems Association.

Ialongo, N., Poduksa, J., Werthamer, L., \& Kellam, S. (2001). The distal impact of two first grade interventions on conduct problems and disorder in early adolescence. Journal of Emotional and Behavioral Disorders, 9, 146-160.
Ialongo, N., Werthamer, L., Kellam, S. G., Brown, C. H., Wang, S., \& Lin, Y. (1999). Proximal impact of two first grade preventive interventions on the early risk behaviors for later substance abuse, depression and antisocial behavior. American Journal of Community Psychology, 27(5), 599-642.

Johnson, V., \& Pandina, R. J. (1993). A longitudinal examination of the relationships among stress, coping strategies, and problems associated with alcohol use. Alcoholism: Clinical and Experimental Research, 17(3), 696-702.

Kellam, S. G., Rebok, G. W., Ialongo, N., \& Mayer, L. S. (1994). The course and malleability of aggressive behavior from early first grade into middle school: Results of a developmental epidemiologic-based prevention trial. Journal of Child Psychology and Psychiatry, 6, 463-481.

Kendler, K. S., Bulik, C. M., Silberg, J., Hettema, J. M., Myers, J., \& Prescott, C. A. (2000). Childhood sexual abuse and adult psychiatric and substance use disorders in women: An epidemiological and cotwin control analysis. Archives of General Psychiatry, 57(10), 953-959.

Kendler, K. S., Neale, M., Kessler, R., Heath, A., \& Eaves, L. (1993). A twin study of recent life events and difficulties. Archives of General Psychiatry, 50(10), 789-796.

Kreek, M. J., \& Koob, G. F. (1998). Drug dependence: Stress and dysregulation of brain reward pathways. Drug and Alcohol Dependence, 51(1-2), 23-47.

Luthar, S. S. (1991). Vulnerability and resilience: A study of highrisk adolesents. Child Development, 62, 600-616.

Masten, A. S., Coatsworth, J. D., Neeman, J., Gest, S. D., Tellegan, A., \& Garmezy, N. (1995). The structure and coherence of competence from childhood through adolescence. Child Development, 66, 1635-1659.

Masten, A. S., Hubbard, J. J., Gest, S. D., Tellegan, A., Garmezy, N., \& Rameriz, M. (1999). Competence in the context of adversity: Pathways to resilience and maladaptation from chilldhood to late adolescence. Child Development, 11, 143169.

McClure, S. M., Laibson, D. I., Loewenstein, G., \& Cohen, J. D. (2004). Separate neural systems value immediate and delayed monetary rewards. Science, 306(5695), 503-507.

McCubbin, J. A., Richardson, J. E., Langer, A. W., Kizer, J. S., \& Obrist, P. A. (1983). Sympathetic neuronal function and left ventricular performance during behavioral stress in humans: The relationship between plasma catecholamines and systolic time intervals. Psychophysiology, 20(1), 102-110.

Moradi, A. R., Doost, H. T., Taghavi, M. R., Yule, W., \& Dalgleish, T. (1999). Everyday memory deficits in children and adolescents with PTSD: Performance on the Rivermead Behavioural Memory Test. Journal of Child Psychololgy and Psychiatry, and Allied Disciplines, 40(3), 357-361.

Morris, J. S., Frith, C. D., Perrett, D. I., Rowland, D., Young, A. W., Calder, A. J., \& Dolan, R. J. (1996). A differential neural response in the human amygdala to fearful and happy facial expressions. Nature, $383,812-815$

Moss, H. B., Talagala, S. L., \& Kirisci, L. (1997). Phosphorus-31 magnetic resonance brain spectroscopy of children at risk for a substance use disorder: Preliminary results. Psychiatry Research, 76(2-3), 101-112.

Muthén, L. K., \& Muthén, B. O. (1998-2004). Mplus user's guide (3rd ed.). Los Angeles, CA: Muthén \& Muthén.

Newcomb, M. D., \& Bentler, P. M. (1988). Impact of adolescent drug use and social support on problems of young adults: A longitudinal study. Journal of Abnormal Psychology, 97(1), 64-75.

Newman, J. P., Patterson, C. M., \& Kosson, D. S. (1987). Response perseveration in psychopaths. Journal of Abnormal Psychology, 96(2), 145-148.

Nichols, S. L., \& Waschbusch, D. A. (2004). A review of the validity of laboratory cognitive tasks used to assess symptoms of 
ADHD. Child Psychiatry and Human Development, 34(4), 297-315.

Paschall, M. J., Fishbein, D. H., Hubal, R. C., \& Eldreth, D. (2004). Psychometric properties of virtual reality vignette performance measures: A novel approach for assessing adolescents' social competency skills. Health Education Research: Theory and Practice, 20(1), 61-70.

Perry, B. D., \& Pollard, R. (1998). Homeostasis, stress, trauma, and adaptation. A neurodevelopmental view of childhood trauma. Child and Adolescent Psychiatric Clinics of North America, 7(1), 33-51.

Petersen, A. C., \& Leffert, N. (1995). Developmental issues influencing guidelines for adolescent health research: A review. Journal of Adolescent Health, 17(5), 298305.

Phillips, M. L., Young, A. W., Senior, C., Brammer, M., Andrew, C., Calder, A. J., Bullmore, E. T., Perrett, D. I., Rowland, D., Williams, S. C., Gray, J. A., \& David, A. S. (1997). A specific neural substrate for perceiving facial expressions of disgust. Nature, 389(6650), 495-498.

Posner, M. (1995). Neuropsychology. Modulation by instruction. Nature, 373(6511), 198-199.

Rogers, R. D., \& Robbins, T. W. (2001). Investigating the neurocognitive deficits associated with chronic drug misuse. Current Opinion in Neurobiology, 11(2), 250-257.

Rogers, R. D., Blackshaw, A. J., Middleton, H. C., Matthews, K., Hawtin, K., Crowley, C., Hopwood, A., Wallace, C., Deakin, J. F., Sahakian, B. J., \& Robbins, T. W. (1999a). Tryptophan depletion impairs stimulus-reward learning while methylphenidate disrupts attentional control in healthy young adults: Implications for the monoaminergic basis of impulsive behaviour. Psychopharmacology (Berlin), 146(4), 482-491.

Rogers, R. D., Owen, A. M., Middleton, H. C., Williams, E. J., Pickard, J. D., Sahakian, B. J., \& Robbins, T. W. (1999b). Choosing between small, likely rewards and large, unlikely rewards activates inferior and orbital PFC. The Journal of Neuroscience, 20, 9029-9038.

Rubia, K., Taylor, E., Smith, A. B., Oksanen, H., Overmeyer, S., Newman, S., \& Oksannen, H. (2001). Neuropsychological analyses of impulsiveness in childhood hyperactivity. The British Journal of Psychiatry: The Journal of Mental Science, 179, 138-143. Erratum in: The British Journal of Psychiatry: The Journal of Mental Science, 179, 272.

Rutter, M. L. (1999). Psychosocial adversity and child psychopathology. The British Journal of Psychiatry: The Journal of Mental Science, 174, 480-493.

Sattler, J. M. (1988). Assessment of children (3rd ed.). San Diego, CA: Sattler.

Sinha, R. (2001). How does stress increase risk of drug abuse and relapse? Psychopharmacology, 158, 343-359.

Slaby, R., \& Guerra, N. (1988). Cognitive mediators of aggression in adolescent offenders: 1. Assessment. Developmental Psychology, 24, 580-588.

Slaby, R. G., \& Wilson-Brewer, R. (1992). Vignettes developed for the evaluation of violence prevention curricula targeting middle school students. Newton, MA: Education Development Center.

Sobel, M. E. (1982). Asymptotic confidence intervals for indirect effects in structural equation models. In S. Leinhardt (Ed.), Sociological methodology 1982 (pp. 290-312). Washington, DC: American Sociological Association.

Solanto, M. V., Abikoff, H., Sonuga-Barke, E., Schachar, R., Logan, G. D., Wigal, T., Hechtman, L., Hinshaw, S., \& Turkel, E. (2001). The ecological validity of delay aversion and response inhibition as measures of impulsivity in
$\mathrm{AD} / \mathrm{HD}$ : A supplement to the NIMH multimodal treatment study of AD/HD. Journal of Abnormal Child Psychology, 29(3), 215-228.

Sonuga-Barke, E. J., Taylor, E., Sembi, S., \& Smith, J. (1992). Hyperactivity and delay aversion-I. The effect of delay on choice. Journal of Child Psychology and Psychiatry, and Allied Disciplines, 33(2), 387-398.

Spear, L. P. (2000). The adolescent brain and age-related behavioral manifestations. Neuroscience and Biobehavioral Reviews, 24, 417-463.

Steckler, T., \& Holsboer, F. (1999). Corticotropin-releasing hormone receptor subtypes and emotion. Biological Psychiatry, 46(11), 480-508.

Tarter, R. E., Vanyukov, M., Giancola, P., Dawes, M., Blackson, T., Mezzich, A., \& Clark, D. B. (1999). Etiology of early age onset substance use disorder: A maturational perspective. Development and Psychopathology, 11, 657-683.

Thadani, P. V. (2002). The intersection of stress, drug abuse and development. Psychoneuroendocrinology, 27(1-2), 221230.

Wechsler, D. (1974). Manual for the Wechsler Intelligence Scale for Children-Revised. San Antonio, TX: The Psychological Corporation.

Wechsler, D. (1991). Wechsler Intelligence Scale for Children-III. San Antonio, TX: The Psychological Corporation

Weiss, F., Ciccocioppo, R., Parsons, L. H., Katner, S., Liu, X. Zorrilla, E. P., Valdez, G. R., Ben-Shahar, O., Angeletti, S., \& Richter, R. R. (2001). Compulsive drug-seeking behavior and relapse. Neuroadaptation, stress, and conditioning factors. Annals of the New York Academy of Sciences, 937, 126.

Weissberg, R. P., Caplan, M. Z., \& Sivo, P. J. (1989). A new conceptual framework for establishing school-based social competence promotion programs. In L. A. Bond \& B. E. Compas (Eds.), Primary prevention and promotion in the schools (pp. 255-296). Newbury Park, CA: Sage.

Weissberg, R. P., \& Greenberg, M. T. (1998). School and community competence-enhancement and prevention programs. In W. Damon (Series Ed.) \& I. E. Sigel \& K. A. Renninger (Vol. Eds.), Handbook of child psychology: Volume 4, Child psychology in practice (5th edn., pp. 877-954). New York: Wiley.

Wills, T. A., McNamara, G., Vaccaro, D., \& Hirky, A. E. (1996) Escalated substance use: A longitudinal grouping analysis from early to middle adolescence. Journal of Abnormal Psychology, 105, 166-180.

Wills, T. A., Sandy, J. M., \& Yaeger, A. M. (2002). Stress and smoking in adolescence: A test of directional hypotheses. Health Psychology, 21(2), 122-130.

Windle, M. (1992). A longitudinal study of stress buffering for adolescent problem behaviors. Developmental Psychology, 28, 522-530.

Young, A., Perrett, D., Calder, A., Sprengelmeyer, R., \& Ekman, P. (2002). Facial expressions of emotion. England: Harcourt Assessment, The Psychological Corporation.

Yung, B., \& Hammond, R. (1998). Breaking the cycle: A culturally sensitive prevention program for African American children and adolescents. In J. Lutzker (Ed.), Handbook of child abuse research and treatment (pp. 319-340). New York, NY: Plenum.

Zins, J. E., Elias, M. J., Greenberg, M. T., \& Weissberg, R. P. (2000). Promoting social and emotional competence in children. In K. M. Minke \& G. C. Bear (Eds.), Preventing school problems - promoting school success: Strategies and programs that work (pp. 71-99). Washington, DC: National Association of School Psychologists. 